\title{
Polypropylene/Clay Nanocomposites Produced by Shear Controlled Orientation in Injection Moulding: Deformation and Fracture Properties
}

\author{
Alejandra Costantino 1 -Valeria Pettarin ${ }^{1,}{ }^{*}-$ Julio Viana $^{2}-$ Antonio Pontes $^{2}-$ Antonio Pouzada $^{2}-$ Patricia Frontini $^{1}$ \\ ${ }^{1}$ National University of Mar del Plata, Institute of Science and Technology of Materials, Argentina \\ 2 University of Minho, Institute for Polymers and Composites, Portugal
}

The effect of distinct morphologies induced by shear controlled orientation in injection moulding (SCORIM) in the mechanical and fracture performance of polypropylene (PP) and PP/nanoclay mouldings is examined in this work. The effect of high shear conditions applied during processing was assessed. Samples exhibited a range of fracture stability ranging from a modest non-linearity to a quasi-stable regime depending on material type and injection conditions. Neat PP showed non-linear brittle behaviour while nanocomposites exhibited quasi-stable behaviour induced by the large deformation capability of the skin layer. Despite the fracture initiating at practically the same loading levels, the propagation energy varied with processing conditions and nanoclay content. The reduction of the core layer achieved by the SCORIM processing along with the differences between the skin and core favoured by the presence of nanoclay are responsible for the toughening of the SCORIM PP/nanoclay thick mouldings.

Keywords: nanocomposites, polypropylene, SCORIM, fracture

\section{INTRODUCTION}

Clays containing polymer nanocomposites are an alternative to conventional microcomposites due to improved mechanical, thermal, and processing properties as well as enhanced flammability resistance and barrier properties at very low filler loadings $(<5$ $\mathrm{wt} \%)$. However, nanocomposites need sufficient stiffness, strength and toughness to meet particular design requirements. In structural and semi-structural applications of these materials, adequate fracture toughness, in addition to high stiffness and mechanical strength, is often required. The design of structural parts, their connecting and assembly may be based on fracture mechanical approaches.

From an industrial perspective, the preparation of thermoplastic polymer nano-composites by melt blending using conventional plastics compounding equipment remains the solution of choice, especially when commodity polymers like polypropylene (PP), which is of great interest for the packaging and automotive industries, are used [1] to [4].

A lot of effort has been focused on the performance of PP nanocomposites prepared by melt compounding [5] to [8]. Manufacturing of PP/ nanoclay composites using conventional injection moulding (CIM) is not an easy task. Mouldings usually displayed poor nanoclay dispersion since the imposed thermomechanical conditions do not generate large enough stress fields to deagglomerate/ exfoliate the clay agglomerates completely [7] and [8]. Besides poor dispersion, the presence of voids and defects in thick specimens is a common feature in many industrial mouldings. In fact, when PP/nanoclay thick specimens are obtained by CIM, large voids are generated during processing. These samples show an apparently stable fracture with a crack arrest regime induced by the presence of the large voids. These voids show partially relaxed triaxiality so that the samples reach different maximum load values in each case (see examples shown in Fig. 1 for the single edge notched bending (SENB) fracture test). As a consequence, it is very difficult to establish a reliable fracture parameter to be used in design calculations and prediction of part performance.

Alternatively to CIM, the shear control orientation in injection moulding (SCORIM) process has been shown to offer potential benefits to the injection moulding process by controlling the microstructure of the moulded materials [9] and [10]. Significant and simultaneous improvements in the stiffness, strength and toughness, the better alignment of fillers, fibres and macromolecules, the moulding to closer tolerances, the enhancement of dimensional stability and reproducibility, the improvement in the aesthetic of the parts, the elimination of microcracks and voids in the mouldings, and the elimination of internal weld lines and sink marks have been reported for PP and other semicrystalline polymers [11]. However, little research effort has been devoted to the moulding of polymer nanocomposites by SCORIM. In fact, the high shear levels applied during SCORIM is expected to lead to better in-process dispersion and orientation of the fillers in the nanocomposite.

In addition, there are previous promising findings on the use of SCORIM to manufacture 
PP/nanoclay composites [12] to [15], which have encouraged us to conduct the present research. Our results showed that for PP, which is a semicrystalline polymer, nanoclay acts as a morphology director, and the concomitant use of SCORIM and nanoclays results in distinct morphologies [16]. Nanoclays act as $\alpha$ - and $\gamma$-phase nucleating agents, increasing the degree of epitaxiality in the skin of the PP/nanoclay mouldings. When compared with CIM, SCORIM results in a higher degree of crystallinity of the skin layer. SCORIM mouldings exhibit a well-defined 'shear' -core structure: a centre-core that occupies less space in comparison with typical CIM moulded parts and a larger shear zone. When the nanoclay is added, an interesting multilayered structure occupies more than two times the thickness of the shear zone of the PP/nanoclay pieces, i.e. there is even less core. It is therefore expected that these changes will be reflected in the mechanical and fracture properties of the mouldings.

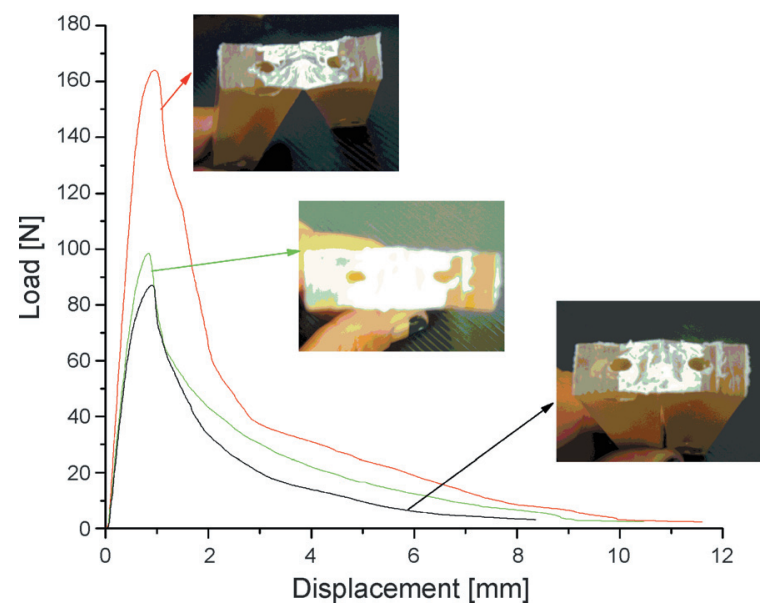

Fig. 1. Load vs. displacement curves for equivalent PP/nanoclay mouldings processed by CIM; differences in the flexural loaddisplacement curves for equivalent fracture samples are clearly seen

The present work investigates the effect of distinct morphologies induced by SCORIM in the mechanical and fracture performance of the $\mathrm{PP} /$ nanoclay mouldings.

\section{MATERIALS AND METHODS}

\subsection{Sample Manufacturing and Microstructural Characteristics}

Compounds were based on Domolen 1100L homopolymer PP and 6, 10 and $14 \%$ of P-802 Nanocor masterbatch of $50 \%$ PP / 50\% nanoclay
(MB). The materials were first blended in a drum rotating at $60 \mathrm{rpm}$. Double edge gated parallelepiped bars of $130 \times 13 \times 8 \mathrm{~mm}$ were injection moulded using a Ferromatik Milacron K-85A injection moulding machine, equipped with a SCORIM mould with a manifold and hydraulic system, which manipulates the melt inside the mould impression. The hydraulic pistons operating in various modes displace the melt during the holding phase of the moulding process, shearing the solid/melt interface and aligning fillers and polymer molecules.

Table 1. Variable injection processing set-up for SCORIM

\begin{tabular}{cccc}
\hline Run & Stroke time & Melt temperature & Stroke number \\
\hline 1 & $1(1 \mathrm{~s})$ & $1\left(200^{\circ} \mathrm{C}\right)$ & $1(3)$ \\
\hline 2 & 1 & $2\left(220^{\circ} \mathrm{C}\right)$ & $2(7)$ \\
\hline 3 & 1 & $3\left(240^{\circ} \mathrm{C}\right)$ & $3(13)$ \\
\hline 4 & $2(2 \mathrm{~s})$ & 2 & 3 \\
\hline 5 & 2 & 3 & 1 \\
\hline 6 & 2 & 1 & 2 \\
\hline 7 & $3(3 \mathrm{~s})$ & 3 & 2 \\
\hline 8 & 3 & 1 & 3 \\
\hline 9 & 3 & 2 & 1 \\
\hline
\end{tabular}

The moulding programme was defined according to a design of experiments (DOE) based on a 3-level factorial array (Table 1). The processing parameters considered were melt temperature (200, 220 and $240{ }^{\circ} \mathrm{C}$ ), stroke time (i.e., piston movement time of 1,2 and $3 \mathrm{~s}$ ) and stroke number (i.e., number of piston movements: 3, 7 and 13). The other injection moulding parameters were kept constant: a mould temperature of $30^{\circ} \mathrm{C}$, an injection pressure of $15 \mathrm{MPa}$, an injection velocity of $10 \mathrm{~mm} / \mathrm{s}$, a holding pressure of 5.3 $\mathrm{MPa}$ and a cooling time of $30 \mathrm{~s}$. Details are as reported in [16].

A complete characterisation of the microstructure of these mouldings has already been reported [16]. An intercalated PP/nanoclay structure was obtained with an intergallery space of $13.4 \mathrm{~nm}$ for all systems, as calculated from the (001) peak of X-ray diffraction patterns using the Bragg's law $\left(\lambda=2 d_{001} \sin \theta_{001}\right)$. Several characteristics of PP morphology were analyzed and two of them are crucial: the degree of orientation of $\alpha$-PP crystallites and the amount of $\gamma$-PP phase in the skin layer. The degree of orientation of $\alpha$-PP was quantified by means of $A_{110}=I \alpha_{(110)} /\left(I \alpha_{(110)}+I \alpha_{(111)}+I \alpha_{(131)+(041)}\right)$, which gives an indication of the orientation roughly parallel to the $c$-axis of the crystallites, which in this case corresponds to the flow direction in the injected samples. $I_{i}$ is the $i$ peak height of XRD after background subtraction. A strong increase in the 
$I \alpha_{(040)} / I \alpha_{(110)}$ ratio for the SCORIM PP-nanoclay samples was found. This indicates that in SCORIM mouldings the nanoclay induced the orientation of the $\alpha$ crystalline-phase of PP in the (040) direction - i.e. increased the degree of epitaxiality [17] - and imparted a low level of crystalline phase orientation in the flow direction. Values of the $A_{110}$ index are presented in Table 2. Regarding the effect of the SCORIM processing conditions on the morphology development, it was found that $A_{110}$ increases with high shearing, and decreases with low shearing and low melt temperatures.

The content of the crystalline $\gamma$-phase was determined using the following equation $G=I \gamma_{(117)} /\left(I \gamma_{(1117)}+\left(I \alpha_{(130)}\right)\right)$ and the results are shown in Table 2. The amount of $\gamma$ increases with MB content in an asymptotic way to a maximum value, which is in agreement with other authors who have claimed that nanoclay [18] to [22] and SCORIM [23] promote the formation of $\gamma$-phase PP crystallites. The nanoclay changes the equilibrium state of the polymer (conformation) and it provides favorable sites for possible epitaxial growth of the $\gamma$-phase because the lattice mismatch is less than $10 \%$ [19]. Moreover, $\gamma$ crystals are nucleated and grow epitaxially on the lateral (010) faces of the $\alpha$ crystal [24] and appear to be favored by, or linked to, the absence of chain folding [25]. The mobility of the PP-MA matrix is significantly reduced in the presence of maleic anhydride grafting in the main chain (present in $\mathrm{MB}$ ), which causes a decrease in chain folding. In the presence of clay particles in polymer nanocomposites, the movement of polymer chains inside the clay particles is restricted. The correlation length of the clay particles is roughly the same as that of the radius of gyration of the matrix. Thus, the formation of the $\gamma$-phase is enhanced in the presence of clay particles [21] and [22].

Table 2. Orientation indexes and $\gamma$-PP content for SCORIM samples

\begin{tabular}{|c|c|c|c|}
\hline Run & $A_{110}(P P / M B-6)$ & Material & $G$ \\
\hline 1 & 0.158 & PP & 0 \\
\hline 2 & 0.165 & PP/MB-6 & 0.48 \\
\hline 3 & 0.186 & PP/MB-10 & 0.52 \\
\hline 4 & 0.187 & PP/MB-14 & 0.55 \\
\hline 5 & 0.194 & & \\
\hline 6 & 0.200 & & \\
\hline 7 & 0.189 & & \\
\hline 8 & 0.190 & & \\
\hline 9 & 0.189 & & \\
\hline
\end{tabular}

For more information about the macro and microstructure of these mouldings readers are referred to $[16]$.

\subsection{Mechanical Performance}

The yield stress of the material in the mouldings was determined in compression using prismatic specimens of rectangular cross section ( $h=10 \mathrm{~mm}, h / L=1.5 \mathrm{~h}$, and $L$ being the height and the width of the sample). These samples were cut out from moulded parts. Smooth and parallel faces were obtained by machining. The tests were performed using an Instron 4467 universal testing machine, at $1 \mathrm{~mm} / \mathrm{min}$ and room temperature. To avoid the eventual influence of voids developed during injection moulding, the start of the plastic domain, i.e. the start of yielding, was considered to be the end of the linear portion of the stress-strain plot [26]. The flexural modulus was measured according to the ASTM D 790-03 standard, at $5 \mathrm{~mm} / \mathrm{min}$ and room temperature. At least five samples of each processing condition were tested.

\subsection{Fracture Characterisation}

The fracture characterisation was performed on SENB deformed in 3-point bending at room temperature at a constant crosshead velocity of $5 \mathrm{~mm} / \mathrm{min}$ in the Instron 4467. Specimens with span, $\underline{S}$, and width, $W$, of 52 and $13 \mathrm{~mm}$, respectively, were prepared by machining from the injected bars. Sharp notches were introduced using a Notchvis Ceast machine with a sharp fly cutter (tip radius less than $12 \mathrm{~mm}$ ) to reach a crack-to-depth ratio $(\mathrm{a} / \mathrm{W})$ equal to 0.5 .

The fracture initiation was evaluated from the critical stress intensity factor in mode $I, K_{I C}$, (Eq. (4)) using load-line displacement plots and the crack length:

$$
K_{I C}=\frac{P}{B W^{1 / 2}} f(a / W),
$$

where $P$ is the load, $B$ is the sample breadth, $W$ is the sample width, $a$ is the crack length and $f(a / W)$ is a dimensionless function of $a / W$ according to ASTM D 5045.

Due to the non-linearity of the load-displacement plots, $P$ was determined at the intersection of a straight line with a compliance of $5 \%$ greater than that of the initial compliance and the load-displacement trace. In every case the geometry validity requirements were met according to [27]: 


$$
B, a,(W-a) \geq 2.5 \cdot\left(\frac{K}{\sigma_{y}}\right)^{2} .
$$

The value of the $J$ integral was computed from:

$$
J=\frac{2 \cdot U}{B(W-a)} .
$$

The energy, $U$, was computed by the integration of the load-displacement traces up to the maximum load point $\left(J_{\max }\right)$ and up to the instability load point $\left(J_{c}\right)$ [28]. This value of $J$ was computed to designate the point of unstable fracture, or loss of structural integrity, in samples displaying quasi-stable crack propagation.

\section{RESULTS AND DISCUSSION}

\subsection{Deformation Performance}

The yield stress of PP nanocomposites was slightly larger than in neat PP, but varied very little with the nanoclay content (Fig. 2). The trends reported in the literature are contradictory, reporting either an increase or a decrease in properties with the addition of nanoclay [29].

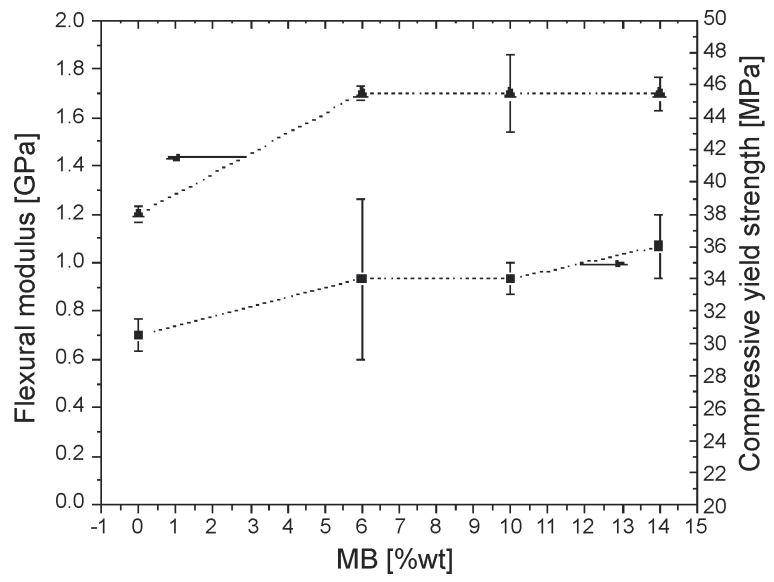

Fig. 2. Mechanical properties of PP nanocomposites

A quite significant increase in the flexural modulus of nanocomposites in comparison with neat PP was also found, on the order of 35 to $40 \%$ (Fig. 2). From theoretical predictions using the MoriTanaka composite micromechanical model, it is possible to estimate an increase in the elastic modulus of PP with 3 to $6 \%$ of nanoclay of the same order [30]. For lower incorporation of nanoclay, in the range between 1 and $6 \%$, the variations in the elastic modulus are negligible, an increase being observed thereafter. Besides the amount of nanoclay, the intercalated nanoclay morphology may also restrict the mobility of the polymer chains and contribute to improvement in the modulus. Furthermore, in flexural tests, the mechanical response is governed by the most exterior layer, i.e. the skin of injected samples. In these samples, the PP microstructure of the skin layer changed with the addition of nanoclay, although the microstructural features are independent of the nanoclay content [16]. Due to the segregation effect of the nanoclay in the skin, it seems that the effective content of nanoclay is similarly independent of $\mathrm{MB}$ concentration [16], and hence the modulus. This can be corroborated by observing the skin zone using Transmission Electron Microscopy (TEM) (as shown in Fig 3). A marked nanoclay orientation along the flow direction in the skin layer of the injected samples is visible, but complete exfoliation cannot be observed either in the skin or the core zones.

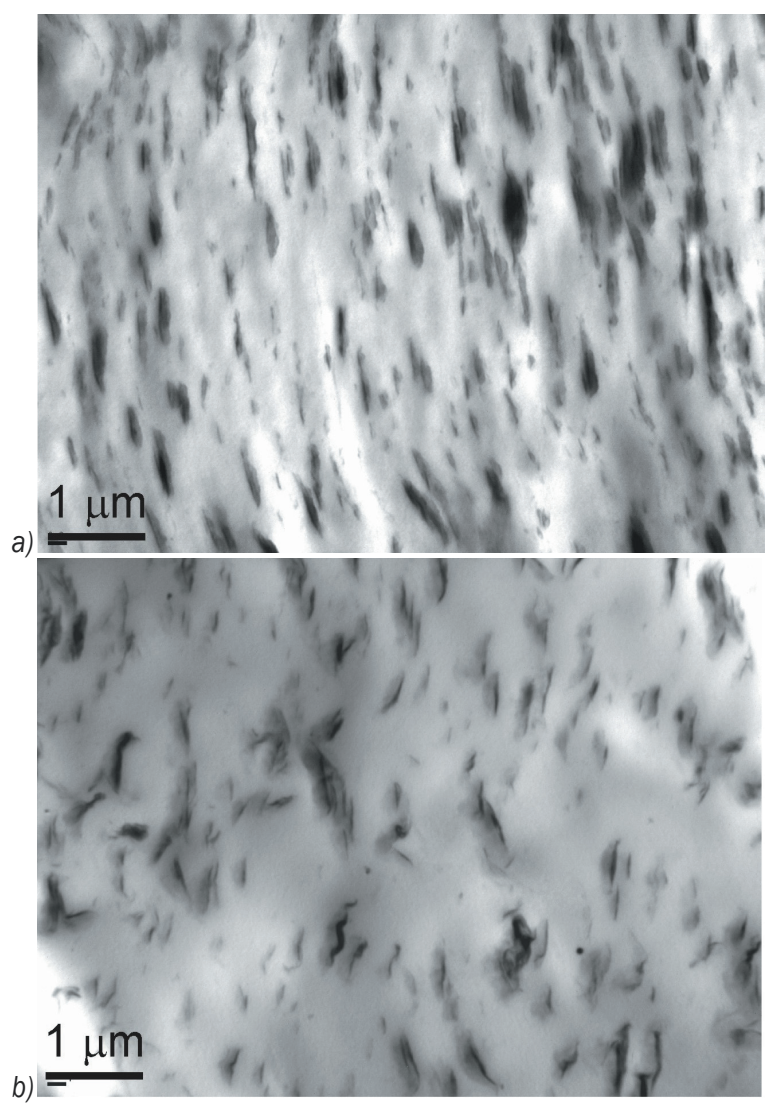

Fig. 3. TEM images of PP/MB-5: a) skin, and b) core

\subsection{Fracture Performance}

The samples exhibited different fracture stabilities ranging from a modest non-linearity to a quasi-stable regime. The fracture regime depends on the type of 
material and the injection moulding conditions (Fig. 4).

PP shows a non-linear behaviour and unstable brittle fracture after reaching the maximum load. The load-displacement curves dropped to zero immediately after reaching the maximum load with relatively short displacement (Fig. 4).
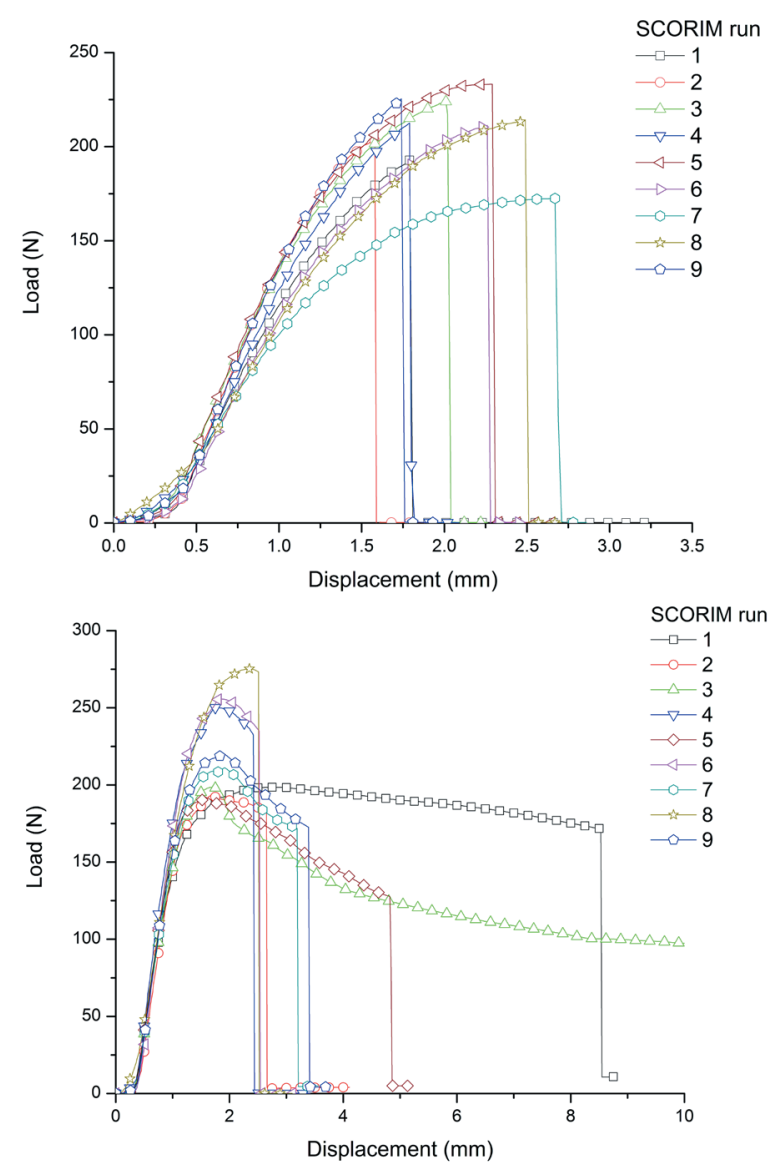

Fig. 4. Fracture load vs displacement curves for SCORIM injected a) $P P$ and b) $P P / M B-6$ respectively

The composite mouldings produced by SCORIM were of acceptable quality and showed various loaddisplacement patterns. Most of the samples exhibited a quasi-stable behaviour: the load increased nonlinearly, and then it kept constant up to a certain displacement when a drastic drop occurred (Fig. 4). Moreover, in most of the samples a large deformation of the skin layer was observed (Fig. 5). It should be mentioned here that this 'skin effect' is characterised by tail instability load-displacement curves, which have already reported for PP based systems [31] and [32]. This large deformation of the skin layer may be related to the high level of molecular and nanoclay orientation (Fig. 3) that favours the sliding of the macromolecules (fostered by the oriented nanoclays), thus improving the deformation capability. In fact, we must point out that the occurrence of necking is likely a combined effect of: the skin/core ratio, the skin orientation level, and possibly the morphology rearrangement in the skin region under different loading directions, which are also influenced by the heat evolution and the dissipation processes. Since SCORIM induces a thicker multi-layered skin in the PP/nanoclay mouldings [16], the 'skin effect' is favoured. This phenomenon leads to differences in the load-displacement curves, promoting a more stable crack propagation followed by a necking phase with a much larger extension [8], [32] and [33]. When voids appear in the fracture surface, they inhibit or instabilize the 'skin-effect' due to stress concentration.

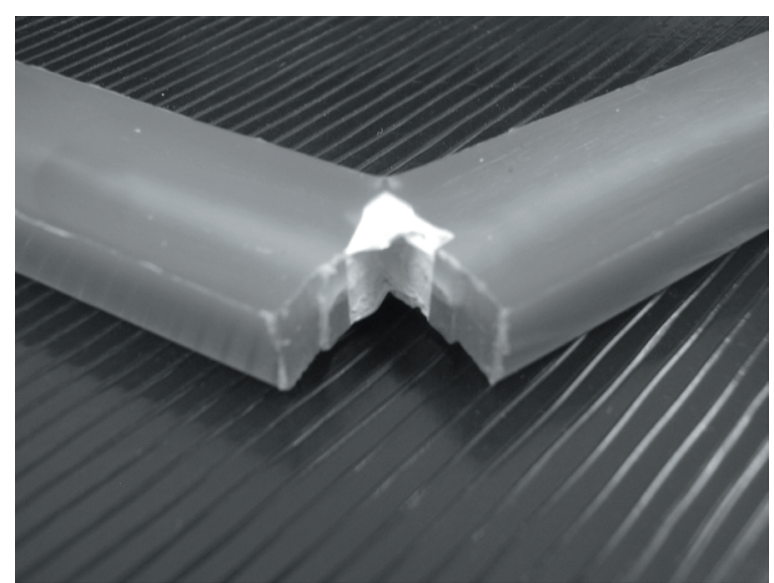

Fig. 5. $P P / M B-6$ sample after the fracture test: note the highly deformed skin without fracture

For these PP/nanoclay composites, small differences were seen in the $K_{I C}$ and $J_{\max }$ (which are related to the fracture initiation) (Table 2), while large differences were seen in the $J_{c}$ (which is related to fracture propagation) (Table 3 ), in comparison with neat PP samples. Replicas of each condition show significant scatter originating from a combination of different causes. The differences observed are typical of semicrystalline polymers injection mouldings that are influenced by microstructural parameters, which include crystalline structure, degree of crystallinity, supermolecular structure, and skin-core configuration [34]. In addition, PP systems are considered to be in the ductile-to-brittle transition regime at room temperature, which implies a larger scatter [35] due to dissimilar contributions of the plastics melt flow and the stable crack growth seen in different specimens of the same set. 
Table 2. Initiation fracture parameters of the mouldings

\begin{tabular}{ccccc}
\hline & \multicolumn{2}{c}{$K_{\text {IC }}\left[\mathrm{MPa} \cdot \mathrm{m}^{1 / 2}\right]$} & \multicolumn{2}{c}{$J_{\max }[\mathrm{N} / \mathrm{mm}]$} \\
\hline Run & $\mathrm{PP}$ & $\mathrm{PP} / \mathrm{MB}-6$ & $\mathrm{PP}$ & $\mathrm{PP} / \mathrm{MB}-6$ \\
\hline 1 & $1.4 \pm 0.2$ & $1.6 \pm 0.3$ & $6.7 \pm 1$ & $10.25 \pm 3.7$ \\
\hline 2 & $1.45 \pm 0.3$ & $1.5 \pm 0.3$ & $6 \pm 1$ & $7 \pm 0.8$ \\
\hline 3 & $1.25 \pm 0.1$ & $1.3 \pm 0.2$ & $7 \pm 1$ & $5 \pm 2$ \\
\hline 4 & $1.5 \pm 0.3$ & $1.6 \pm 0.1$ & $11 \pm 8.7$ & $7.75 \pm 1$ \\
\hline 5 & $1.3 \pm 0.2$ & $1.4 \pm 0.3$ & $7.2 \pm 1.6$ & $5 \pm 1.2$ \\
\hline 6 & $1.3 \pm 0.1$ & $1.7 \pm 0.2$ & $8.4 \pm 1.9$ & $7.5 \pm 2$ \\
\hline 7 & $1.3 \pm 0.2$ & $1.6 \pm 0.1$ & $8.8 \pm 3.8$ & $7.3 \pm 1.5$ \\
\hline 8 & $1.6 \pm 0.4$ & $1.8 \pm 0.1$ & $8.4 \pm 2.1$ & $11 \pm 2.5$ \\
\hline 9 & $1.2 \pm 0.1$ & $1.4 \pm 0.3$ & $6 \pm 1.2$ & $6.5 \pm 2$ \\
\hline
\end{tabular}

Table 3. $J_{c}$ data for the mouldings

\begin{tabular}{ccccc}
\hline \multirow{2}{*}{ Run } & \multicolumn{4}{c}{$J_{C}[\mathrm{~N} / \mathrm{mm}]$} \\
\cline { 2 - 5 } & \multicolumn{2}{c}{ All samples } & \multicolumn{2}{c}{ Samples with no visible defects } \\
\cline { 2 - 5 } & $\mathrm{PP}$ & $\mathrm{PP} / \mathrm{MB}-6$ & $\mathrm{PP}$ & $\mathrm{PP} / \mathrm{MB}-6$ \\
\hline 1 & $6.7 \pm 1$ & $58.2 \pm 35.9$ & $6.7 \pm 1$ & $94.5 \pm 7.8$ \\
\hline 2 & $6 \pm 1$ & $20 \pm 13.7$ & $6 \pm 1$ & $*$ \\
\hline 3 & $7 \pm 1$ & $54 \pm 25.8$ & $7 \pm 1$ & $65.5 \pm 3$ \\
\hline 4 & $11 \pm 8.7$ & $10.8 \pm 3.5$ & $7.2 \pm 0.9$ & $8.3 \pm 1.2$ \\
\hline 5 & $7.2 \pm 1.6$ & $14.8 \pm 8$ & $6.5 \pm 0.6$ & $23.5 \pm 2.1$ \\
\hline 6 & $8.4 \pm 1.9$ & $10.4 \pm 3.3$ & $8.4 \pm 1.9$ & $10.4 \pm 3.2$ \\
\hline 7 & $8.8 \pm 3.8$ & $11.3 \pm 4.7$ & $7 \pm 0.01$ & $9 \pm 1.7$ \\
\hline 8 & $8.4 \pm 2.1$ & $40.4 \pm 35.4$ & $8.4 \pm 2.1$ & $78.5 \pm 13$ \\
\hline 9 & $6 \pm 1.2$ & $16.4 \pm 11.9$ & $6 \pm 1.2$ & $*$ \\
\hline
\end{tabular}

* Neglected behaviour

The addition of nanoclay improved the fracture performance of the SCORIM PP/nanoclay samples thanks to the differences induced by the fillers in the microstructure: as we stated previously [16], the fillers refine the crystal structure and orient the $\alpha$-PP crystals thus promoting epitaxial growth of the $\gamma$-phase, which improves toughness [18]. With regard to this last point, several studies have demonstrated the coexistence and concurrent growth of $\alpha$ and $\gamma$ lamellae, and that there is a continual decrease in lamellar thickness with $\gamma$ content [36]. It has also been shown that toughness decreases linearly with the reciprocal value of lamellar thickness [37]. Moreover, polypropylenes with high contents of the $\gamma$ phase show behavior typical of stiff-plastic materials, i.e. a high value of the elastic modulus but with high ductility [38]. Therefore, it is concluded that the generated $\gamma$-phase in the skin of the samples induces a large-scale plastic deformation of the skin with consequent tearing of matrix ligaments leading to fibrillation and enhanced toughness.

The best global results (skin effect with a high value of $J$ and acceptable reproducibility) were achieved using processing conditions that imply low injection temperature and shear forces.
The ANOVA analysis of the results indicates that the increment of the shear level (higher stroke number and longer time) leads to a decrease in $J_{c}$. The correlation of these results with the results of the processing induced morphology [16] seems to indicate that the most relevant morphological feature is the level of orientation at the skin in the flow direction: higher orientation levels lead to lower toughness (see Fig. 6), keeping in mind that higher orientation implies higher $\gamma$-PP content.

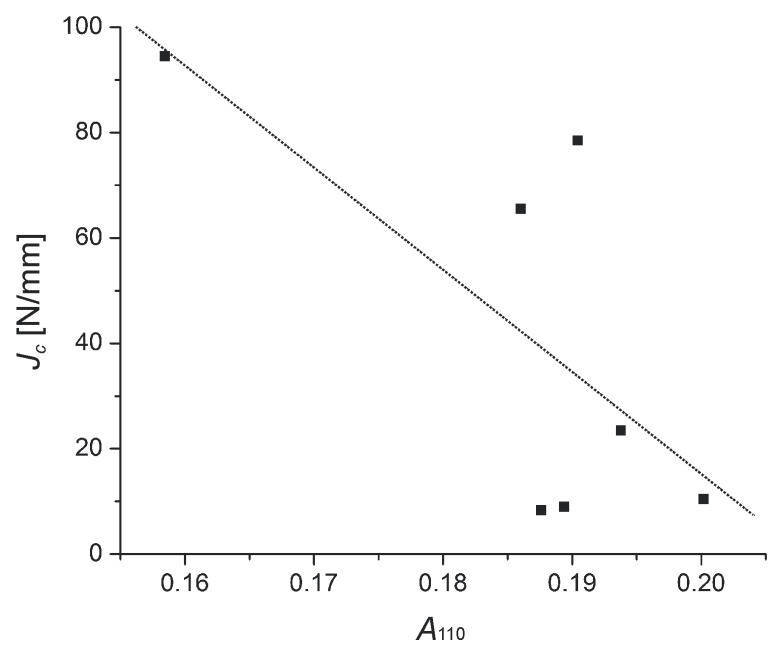

Fig. 6. Influence of skin orientation of PP crystallites $\left(A_{110}\right)$ on toughness of $P P / M B-6$

\section{CONCLUSIONS}

The characterisation of $\mathrm{PP} /$ nanoclay mouldings produced by SCORIM leads to the following conclusions:

The SCORIM mouldings of neat PP showed a nonlinear brittle behaviour, whereas PP nanocomposites exhibited a quasi-stable behaviour induced by a larger deformability of the skin layer. Despite the fracture initiating at practically the same loading levels, the overall crack propagation energy values varied as a function of the processing conditions.

The statistical analysis indicates that the reduction in core size achieved in the SCORIM processing, along with the differences between the skin (or shear zone) and core zones, and the favourable effect of the presence of nanoclays, are responsible for the improvement in the toughness of the SCORIM PP/ nanoclay thick samples.

\section{REFERENCES}

[1] Alexandre, M., Dubois, P. (2000). Polymer-layered silicate nanocomposites: preparation, properties and 
uses of a new class of materials. Materials Science and Engineering: R: Reports, vol. 28, no. 1-2, p. 1-63., DOI:10.1016/S0927-796X(00)00012-7.

[2] Manias, E., Touny, A., Wu, L., Strawhecker, K., Lu, B., Chung, T.C. (2001). Polypropylene / Montmorillonite nanocomposites. review of the synthetic routes and materials properties. Chemistry of Materials, vol. 13, no. 10, p. 3516-3523, DOI:10.1021/cm0110627.

[3] Paul, D.R., Robeson, L.M. (2008). Polymer nanotechnology: Nanocomposites. Polymer, vol. 49, no. 15, p. 3187-3204, DOI:10.1016/j.polymer.2008.04.017.

[4] Ciardelli, F., Coiai, S., Passaglia, E., Pucci, A., Ruggeri, G. (2008). Nanocomposites based on polyolefins and functional thermoplastic materials. Polymer International, vol. 57, no. 6, p. 805-836, DOI:10.1002/ pi.2415.

[5] Li, J., Ton-That, M.T., Leelapornpisit, W., Utracki, L.A. (2007). Melt compounding of polypropylenebased clay nanocomposites. Polymer Engineering and Science, vol. 47, p. 1447, DOI:10.1002/pen.20841.

[6] Peltola, P., Valipakka, E., Vuorinen, J., Syrjala, S., Hanhi, K. (2006). Effect of rotational speed of twin screw extruder on the microstructure and rheological and mechanical properties of nanoclay-reinforced polypropylene nanocomposites Polymer Engineering and Science, vol. 46, p. 995, DOI:10.1002/pen.20586.

[7] Pettarin, V., Viau, G., Fasce, L., Viana, J.C., Pontes, A.J., Frontini, P.M., Pouzada, A.S. (2013). Uni- and biaxial impact behavior of double-gated nanoclayreinforced polypropylene injection moldings. Polymer Engineering and Science, vol. 53, no. 4, p. 724-733. DOI:10.1002/pen.23306.

[8] Pettarin, V., Brun, F., Viana, J.C., Pouzada, A.S., Frontini, P.M. (2013). Toughness distribution in complex PP/nanoclay injected mouldings. Composites Science \& Technology, vol. 74, p. 28-36, DOI:10.1016/j. compscitech.2012.09.015.

[9] Kalay, G., Bevis, M.J. (1997). Processing and physical property relationships in injection-molded isotactic polypropylene. 2. Morphology and crystallinity. Journal of Polymer Science Part B: Polymer Physics, vol. 35, no. 2, p. 265-291, DOI:10.1002/(SICI)10990488(19970130)35:2<265::AID-POLB6>3.0.CO;2-R.

[10] Kalay, G., Bevis, M.J. (1997). Processing and physical property relationships in injection-molded isotactic polypropylene. 1. Mechanical properties. Journal of Polymer Science Part B: Polymer Physics, vol. 35, no. 2, p. 241-263, DOI:10.1002/(SICI)10990488(19970130)35:2<241::AID-POLB5>3.0.CO;2-V.

[11] Kikuchi, A., Coulter, J.P., Angstadt, D.C. (2002). Polymer melt manipulation and in-process morphology control during molding processes: A Review. Journal of Injection Molding Technology, vol. 6, no. 2, p. 91.

[12] Bilewicz, M., Viana, J.C., Cunha, A.M., Dobrzański, L.A. (2006). Morphology diversity and mechanical response of injection moulded polymer nanocomposites and polymer-polymer composites. Journal of
Achievements in Materials and Manufacturing Engineering, vol. 15, no. 1-2, p. 156-165.

[13] Bilewicz, M., Viana, J.C., Dobrzański, L.A. (2006). Self reinforced polymer-polymer composites. Journal of Achievements in Materials and Manufacturing Engineering, vol. 24, no. 2, p. 43-46.

[14] Bilewicz, M., Viana, J.C., Dobrzański, L.A. (2008). Development of microstructure affected by inmould manipulation in polymer composites and nanocomposites. Journal of Achievements in Materials and Manufacturing Engineering, vol. 31, no. 1, p. 7176.

[15] Bilewicz, M., Viana, J.C., Dobrzański, L.A. (2008). Polymer composite strengthening by developed injection moulding technique. Archives of Materials Science and Engineering, vol. 30, no. 2, p. 69-72.

[16] Costantino, A., Pettarin, V., Viana, J., Pontes, A., Pouzada, A., Frontini, P. (2012). Microstructure of $\mathrm{PP} /$ clay nanocomposites produced by shear induced injection moulding. Procedia Materials Science, vol. 1, p. 34-43, http://dx.doi.org/10.1016/j. mspro.2012.06.005.

[17] Kim, B., Lee, S.H., Lee, D., Ha, B., Park, J., Char, K. (2004). Crystallization kinetics of maleated polypropylene/clay hybrids. Industrial \&. Engineering Chemistry Research, vol. 43, no. 9, p. 6082-6089, DOI:10.1021/ie049825y.

[18] Yuan, Q., Deshmane, C., Pesacreta, T.C., Misra, R.D.K. (2008). Nanoparticle effects on spherulitic structure and phase formation in polypropylene crystallized at moderately elevated pressures: The influence on fracture resistance. Materials Science and Engineering A, vol. 480, p. 181-188, DOI:10.1016/j. msea.2007.07.019.

[19] Yuan, Q., Chen, J., Yang, Y., Misra, R.D.K. (2010). Nanoparticle interface driven microstructural evolution and crystalline phases of polypropylene: The effect of nanoclay content on structure and physical properties. Materials Science and Engineering A, vol. 527, p. 6002-6011, DOI:10.1016/j.msea.2010.05.085.

[20] Solomon, M.J., Somwangthanaroj, A. (2004). Intercalated Polypropylene Nanocomposites. Dekker Encyclopedia of Nanoscience and Nanotechnology, Marcel Dekker, Inc. p. 1483-1490

[21] Nam, P.H., Maiti, P., Okamoto, M., Kotaka, T., Hasegawa, N., Usuki, A. (2001). A hierarchical structure and properties of intercalated polypropylene/ clay nanocomposites. Polymer, vol. 42, p. 9633-9640, DOI:10.1016/S0032-3861(01)00512-2.

[22] Maiti, P., Nam, P.H., Okamoto, M., Kotaka, T. (2002). The effect of crystallization on the structure and morphology of polypropylene/clay nanocomposites. Polymer Engineering \& Science, vol. 42, no. 9, p. 1864-1871, DOI:10.1002/pen.11079.

[23] Kalay, G., Zhong, Z., Allan, P., Bevis, M.J. (1996). The occurrence of the $\gamma$-phase in injection moulded polypropylene in relation to the processing 
conditions. Polymer, vol. 37, no. 11, p. 2077-2085, DOI:10.1016/0032-3861(96)85852-6.

[24] Lotz, B., Graff, S., Wittmann, J.C. (1986). Crystal morphology of the $\gamma$ (triclinic) phase of isotactic polypropylene and its relation to the $\alpha$ phase. Journal of Polyrner Science Part B: Polymer Physics, vol. 24, no. 9, p. 2017-2032, DOI:10.1002/polb.1986.090240909.

[25] Kressler, J. (1999). Gamma-phase of isotactic polypropylene. Karger-Kocsis, J. (ed.) Polypropylene: An A-Z Reference, p. 267-272.

[26] Cauvin, L., Kondo, D., Brieu, M., Bhatnagar, N. (2010). Mechanical properties of polypropylene layered silicate nanocomposites: Characterisation and micro-macro modelling. Polymer Testing, vol. 29, no. 2, p. 245-250, DOI:10.1016/j.polymertesting.2009.11.007.

[27] Williams, J.G., Cawood, M.J. (1990). European group on fracture: $\mathrm{Kc}$ and $\mathrm{G}_{\mathrm{c}}$ methods for polymers. Polymer Testing, vol. 9, no. 1, p. 15-26, DOI:10.1016/01429418(90)90045-F.

[28] Fasce, L.A., Frontini, P.M., Wong, S.-C., Mai, Y.W. (2004). Polypropylene modified with elastomeric metallocene-catalyzed poly-olefin blends: Fracture behaviour and development of damage mechanisms. Journal of Polymer Science Part B: Polymer Physics, vol. 42, no. 6, p. 1075-1089, DOI:10.1002/polb.10721.

[29] Százdi, L., Pukánszky Jr., B., Vancso, G.J., Pukánszky, B. (2006). Quantitative estimation of the reinforcing effect of layered silicates in PP nanocomposites. Polymer, vol. 47, no. 13, p. 4638-4648, DOI:10.1016/j. polymer.2006.04.053.

[30] Bayar, S., Delale, F., Li, J. (2012). Effect of temperature on mechanical properties of nanoclay reinforced polymeric nanocomposites - Part II: Modeling and theoretical predictions. Report Documentation Page of The City College of New York .

[31] Karger-Kocsis, J., Mouzakis, D.E. (1999). Effects of injection molding-induced morphology on the work of fracture parameters in rubber-toughened polypropylenes. Polymer Engineering \& Science, vol. 39, no. 8, p. 1365-1374, DOI:10.1002/pen.11525.

[32] Karger-Kocsis, J., Friedrich, K. (1989). Effect of skin-core morphology on fatigue crack propagation in injection moulded polypropylene homopolymer. International Journal of Fatigue, vol. 11, no. 3, p. 161168, DOI:10.1016/0142-1123(89)90435-0.

[33] Heino, M., Hietaoja, P., Seppälä, J., Harmia, T., Friedrich, K. (1997). Studies on fracture behavior of tough PA6/PP blends. Journal of Applied Polymer Science, vol. 66, no. 12, p. 2209-2220, DOI:10.1002/ (SICI) 1097-4628(19971219)66:12<2209::AIDAPP2>3.0.CO;2-K.

[34] Aurrekoetxea, J., Sarrionandia, M.A., Urrutibeascoa, I., Maspoch, M.L. (2003). Effects of injection moulding induced morphology on the fracture behaviour of virgin and recycled polypropylene. Polymer, vol. 44, no. 22, p. 6959-6964, DOI:10.1016/S0032-3861(03)00493-2.

[35] Cocco, R.G., Frontini, P.M., Perez Ipi-a, J.E. (2005). Fracture toughness of polymers in the ductile-tobrittle transition region: Statistical approach and lower bound determination. Journal of Polymer Science Part B: Polymer Physics, vol. 43, no. 24, p. 3674-3684, DOI:10.1002/polb.20600.

[36] Anderson Campbell, R., Phillips, P.J., Lin, J.S. (1993). The gamma phase of high-molecular weight polypropylene: 1. Morphological aspects. Polymer, vol. 34 , no. 23 , p. 4809-4816, DOI:10.1016/00323861(93)90002-R.

[37] Van der Meer, D.W. (2003). Structure-Property Relationships in Isotactic Polypropylene. Ph.D. thesis, University of Twente, Enschede.

[38] De Rosa, C., Auriemma, F., Paolillo, M., Resconi, L., Camurati, L. (2005). Crystallization behavior and mechanical properties of regiodefective, highly stereoregular isotactic polypropylene: Effect of regiodefects versus stereodefects and influence of the molecular mass. Macromolecules, vol. 38, p. 91439154, DOI:10.1021/ma051004x. 